\title{
Energy supply and the shape of death in neurons and lymphoid cells
}

\author{
Pierluigi Nicotera $^{1,2}$ and Marcel Leist ${ }^{1}$ \\ ${ }^{1}$ Chair of Molecular Toxicology, Faculty of Biology, University of Konstanz, \\ PO Box 5560-X911, D-78457 Konstanz, Germany \\ 2 corresponding author: Prof. Pierluigi Nicotera MD, PhD, \\ tel: +49 753188 4035; fax: +49 753188 4033; \\ e-mail: Pierluigi.Nicotera@uni-konstanz.de
}

Received 12.3.97; revised 18.3.97; accepted 5.4.97

Edited by G. Melino

\begin{abstract}
Apoptosis and necrosis are considered as conceptually distinct forms of cell death. Nevertheless, there is increasing evidence that classical apoptosis and necrosis represent only the extreme ends of a wide range of possible morphological and biochemical deaths. The two classical types of demise can occur simultaneously in tissues or cell cultures exposed to the same stimulus, and often the intensity of the same initial insult decides the prevalence of either apoptosis or necrosis. This suggests that, while some early events may be common to both types of cell death, a downstream controller may be required to direct cells towards the organised execution of apoptosis. We have recently shown that intracellular energy levels and mitochondrial function are rapidly compromised in necrosis, but not in apoptosis of neuronal cells. Then, we went on to show that pre-emptying human T cells of ATP switches the type of demise caused by two classic apoptotic triggers (staurosporin and CD95 stimulation) from apoptosis to necrosis. Conditions of controlled intracellular ATP depletion, which was obtained by blocking mitochondrial and/or glycolytic ATP generation, were used in combination with repletion of the cytosolic ATP pool with glucose to redirect the death program towards apoptosis or necrosis. At least two distinct steps, the typical nuclear degradation, and the expression of annexin V-recognisable determinants on the cell surface require sufficient ATP generation. This suggests that some upstream regulators of cell death may be common to both types of cell demise, whereas yet unknown downstream processes decide its shape and the implications for the neighbouring tissue.
\end{abstract}

Keywords: ATP; apoptosis; excitotoxicity; glutamate; mitochondria; lamins

Abbreviations: $\mathrm{MPP}^{+}, 1$-methyl-4 phenyl-pyridinium

\section{Mitochondria and neuronal demise}

Several neurodegenerative diseases are characterized by a relentless neuronal demise. Cerebral ischemia or long-lasting neurodegenerative conditions such as Alzheimer's disease $(A D)$, Parkinson's disease (PD), amyotrophic lateral sclerosis (ALS), Huntington's disease (HD), AIDS-related dementia and multiple sclerosis/experimental allergic encephalitis may involve an increased rate of neuronal apoptosis (Bredesen, 1995). One common component in the pathogenesis of these diseases may be excitotoxicity (Choi, 1988, 1992; Meldrum and Garthwaite, 1990; Lipton and Rosenberg, 1994). Generally, excitotoxicity is induced by conditions favouring glutamate-accumulation in the extracellular space (Figure 1), and it is enhanced by conditions (e.g. energy depletion) that hinder cellular protective mechanisms (Choi, 1995; Novelli et al, 1988). Typical conditions leading to increased extracellular glutamate concentrations (Bullock et al, 1995; Rothman, 1984; Sandberg et al, 1986; Drejer et al, 1985; Beneviste et al, 1984) are depolarization of neurons, energy depletion due to hypoglycaemia or hypoxia (Cheng and Mattson, 1991, 1992; Cheng et al, 1994; Wieloch, 1985), exposure to nitric oxide (NO) (Bonfoco et al, 1996; Leist et al, 1997a) or defects in the glutamate reuptake systems (Rothstein et al, 1996). In addition, it has recently become clear that concomitant production of cytokines or other mediators can participate in cerebral damage (Chao et al, 1995; Philippon et al, 1994; Fassbender et al, 1994; Mitrovic et al, 1994).

Circumstantial evidence that mitochondria play important roles in excitotoxicity and also in slowly developing neurodegenerative disorders is abundant. Similar to other neurodegenerative diseases, those that primarily affect mitochondrial energy metabolism (i.e., mitochondrial encephalopathies) feature delayed onset, slow progression, decreased glucose metabolism and finally neuronal loss. Diseases, which are associated with point mutations in mitochondrial DNA seem to share some similarities with $A D$, or $P D$, and point mutations in mitochondrial DNA have occasionally been described in the latter diseases (Beal et al, 1993; Abe et al, 1995). Finally, decline in the activity of enzymes involved in the respiratory chain (e.g., complex I) caused for example by $\mathrm{MPP}^{+}$(Kass et al, 1988; Hartley et al, 1994) and in pathological settings by nitrosative or oxidative stress (Gross and Wolin, 1995) would favour free radical generation, decreased $\mathrm{Ca}^{2+}$ buffering capacity and loss of plasma membrane potential with sensitisation to excitotoxicity (Coyle and Puttfarcken, 1993). This sequela of events may underlie the pathogenesis of PD (Fahn and Cohen, 1992).

In addition to possible pathogenic roles in the initial development of slow neurodegenerative disorders, mitochondrial failure is a consequence of several types of neuronal injury. Excessive glutamate release is a key event in stroke, and circumstantial evidence suggests that accumulation of this neurotransmitter at synaptic clefts occurs also in several other neuropathological conditions. The subsequent $\mathrm{Ca}^{2+}$ overload can elicit neurodisruption directly (i.e. activation of proteases or lipases) or stimulate 


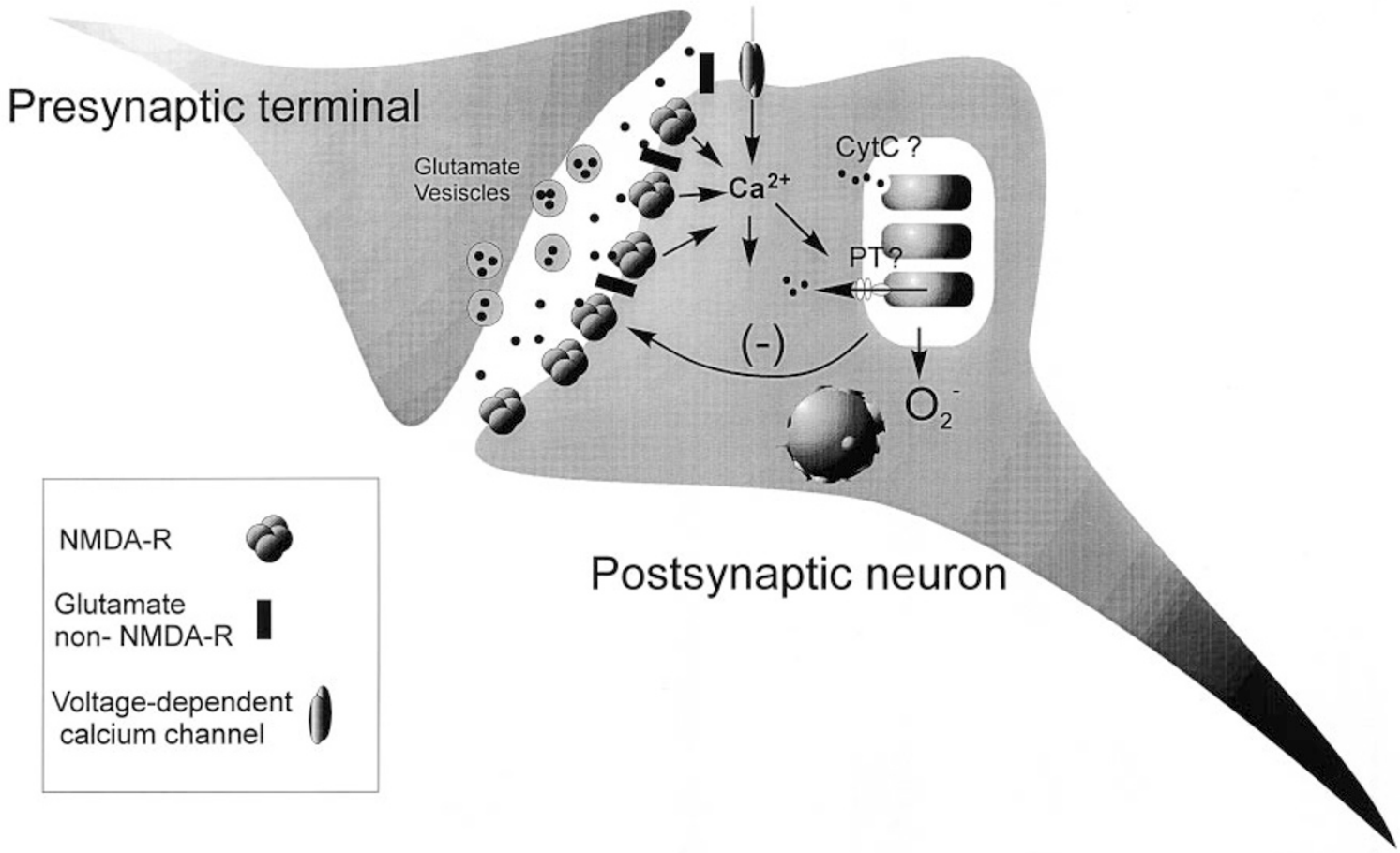

Figure 1 The role of mitochondria in excitotoxicity. Accumulation of glutamate in synaptic clefts by excessive release or deficient reuptake leads to a prolonged increase of $\mathrm{Ca}^{2+}$ in postsynaptic neurons. Glutamate-receptors of both N-methyl-D-aspartate (NMDA-R) and non-NMDA subtypes, as well as voltage-dependent channels contribute to $\mathrm{Ca}^{2+}$-overload. Mitochondria can play multiple roles as modulators of cytotoxicity. They can sequester $\mathrm{Ca}^{2+}$ and indirectly modulate NMDARs and release reactive oxygen species, $\mathrm{Ca}^{2+}$ and proteins involved in apoptosis. (PT) permeability transition; Cyt $\mathrm{C}$ (holocytochrome $\mathrm{C}$ ).

oxidative/nitrosative stress (Prehn et al, 1994; Mattson et al, 1995; Dugan et al, 1995; Reynolds and Hastings, 1995; Lafon-Cazal et al, 1993). Mitochondria participate in the defence against cytosolic $\mathrm{Ca}^{2+}$ overload by sequestering the ion (Gunter and Pfeiffer, 1990; Budd and Nicholls, 1996a). On the other hand, following $\mathrm{Ca}^{2+}$ overload or nitrosative stress they eventually release their $\mathrm{Ca}^{2+}$, generate reactive oxygen, collapse their membrane potential and swell (Gunter and Pfeiffer, 1990). Compromised mitochondria are not only passively involved in cytotoxicity (i.e., because they do not provide the cell with sufficient ATP), but they generate active signals involved in the execution of apoptosis (Liu et al, 1996; Zamzami et al, 1996; Newmeyer et al, 1994; Susin et al, 1996; Yang et al, 1997; Kluck et al, 1997). Thus, mitochondria may act both as buffers or enhancers, either helping cells to recover or accelerating their demise (Figure 1).

\section{Mitochondria and neuronal $\mathrm{Ca}^{2+}$-overload}

$\mathrm{Ca}^{2+}$ is sequestered into mitochondria mainly via a $\mathrm{Ca}^{2+}$ uniporter or via a $\mathrm{Ca}^{2+} / 2 \mathrm{Na}^{+}$antiporter, under conditions of $\mathrm{Na}^{+}$-overload (Gunter and Pfeiffer, 1990; Gunter et al, 1994). The uniporter is driven by the electrochemical membrane potential and has a high capacity, but a relatively low affinity. The lowest level at which brain mitochondria regulate $\left[\mathrm{Ca}^{2+}\right]_{\mathrm{i}}$ is $300 \mathrm{nM}$ in the presence of spermine and may require even higher $\mathrm{Ca}^{2+}$ concentrations $(1 \mu \mathrm{M})$ under unfavourable conditions. Thus, it has been assumed that $\mathrm{Ca}^{2+}$ is imported into mitochondria only during conditions of prolonged stimulation and overload, or when transient high $\mathrm{Ca}^{2+}$ concentrations are created at local sites close to mitochondria. Studies in non-neuronal cells have shown that mitochondria can load $\mathrm{Ca}^{2+}$ during physiological agonist stimulation and may therefore contribute to lower elevated $\left[\mathrm{Ca}^{2+}\right]_{\mathrm{i}}$ (Rutter et al, 1993). Mitochondria have been shown to help reduce considerably elevated $\left[\mathrm{Ca}^{2+}\right]_{\mathrm{i}}$ following stimulation of neurons (White and Reynolds, 1995; Kiedrowski and Costa, 1995; Choi, 1988), and mitochondrial $\mathrm{Ca}^{2+}$-deposits were found in cerebellar granule cells (CGCs), lethally challenged with N-methyl-D-aspartate (NMDA) (Garthwaite and Garthwaite, 1986) or in hippocampal neurons after stroke (Simon et al, 1984). Although ATP production in some neurons (i.e. CGC) may be efficiently provided by glycolysis (Budd and Nicholls, 1996b; Choi, 1988), loss of mitochondrial membrane potential still results in ATP depletion during glutamate excitotoxicity (Ankarcrona et al, 1995). Accordingly, also in the presence of oligomycin to block the mitochondrial ATP synthase, the ATP/ADP ratio falls (Budd and Nicholls, 1996a). This may reflect inhibition of glycolysis due to oxidative stress or the increased demand of ATP for membrane pumps that counteract the massive $\mathrm{Ca}^{2+}$ or $\mathrm{Na}^{+}$overload. Thus, the recovery of ATP levels and mitochondrial function following removal of glutamate (Ankarcrona et al, 1995) would be in line with a decreased $\mathrm{Ca}^{2+}$ load of cytosol and mitochondria. This is in agreement with recent findings 
that mitochondria play a primary role as feedback modulators of excitotoxicity (Budd and Nicholls, 1996b). It was shown that mitochondria would act as $\mathrm{Ca}^{2+}$ sinks, that may lower at least for some time the $\mathrm{Ca}^{2+}$-dependent negative feedback on the NMDA receptor (Legendre et al, 1993; Rosenmund and Westbrook, 1993) and thereby control the influx of $\mathrm{Ca}^{2+}$ in excitotoxicity. Thus, when $\mathrm{Ca}^{2+}$ accumulation in the mitochondria is prevented, the inhibition of the NMDA receptor would be enhanced (Budd and Nicholls, 1996a).

In intact mitochondria, $\mathrm{Ca}^{2+}$-extrusion is an energyrequiring process (33 kJ/mol) (Gunter and Pfeiffer, 1990; Gunter et al, 1994), and may be stimulated by oxidative stress. Oxidation of NADH with subsequent mono-ADPribosylation of mitochondrial proteins or formation of cyclic ADP-ribose have been suggested as regulatory mechanisms. Such stress-enhanced $\mathrm{Ca}^{2+}$-extrusion may be the basis of ' $\mathrm{Ca}^{2+}$ cycling', i.e., continuous uptake and release of $\mathrm{Ca}^{2+}$ by mitochondria, which precedes the dissipation of the membrane potential and mitochondrial failure (Gunter et al, 1994). The interaction of raised $\left[\mathrm{Ca}^{2+}\right]_{i}$ and ROS may therefore lead to a vicious loop, since mitochondria, stressed as a consequence of NMDA-R stimulation (Dugan et al, 1995; Reynolds and Hastings, 1995) and $\mathrm{Ca}^{2+}$-overload (Dykens, 1994), will produce increasing amounts of ROS and $\mathrm{Ca}^{2+}$ cycling, further damaging an already uncoupled respiratory chain.

A mechanism for mitochondrial $\mathrm{Ca}^{2+}$-release fundamentally different from the one described above involves the permeability transition (PT) of mitochondria (reviewed by Zoratti and Szabò, 1995; Kroemer, 1997). PT is associated with the opening of a pore in the inner mitochondrial membrane, which makes it completely permeable to ions and small molecules. Under such conditions, mitochondrial $\mathrm{Ca}^{2+}$ is released without energy-requirement. PT may be induced in excitotoxicity following intracellular $\mathrm{Ca}^{2+}$-overload or oxidative stress and eventually results in the breakdown of mitochondrial membrane potential and swelling of the mitochondria.

PT may be a key switch responsible for the induction of apoptosis (Figure 2). Studies in Dr Kroemer's laboratory have recently suggested that a $50 \mathrm{kDa}$ mitochondrial protein can be released from the intermembrane space during PT, and cause apoptotic-like changes in isolated nuclei (Kroemer, 1997). In this context, it is important to note that energization of mitochondria and maintenance of their membrane potential does not necessarily require a functional respiratory chain. ATP may be imported from the cytosol via the ATP/ADP-translocator and then generate a membrane potential through the oligomycin-sensitive proton pump. Consequently, also mitochondria that are unable to perform oxidative phosphorylation due to the lack of proteins coded by mitochondrial DNA can undergo PT and trigger nuclear apoptotic changes (Zamzami et al, 1996). The observations that during neuronal apoptosis elicited by glutamate, mitochondrial function is only transiently depressed and the initial ATP loss is rectified suggest that a global collapse of mitochondrial membrane potential is not necessary for apoptosis. In view of recent findings from our (Leist et al, 1997c) and Dr Tsujimoto's laboratory (Tsujimoto, 1997), a residual amount of ATP is actually required for the progression towards apoptosis. Thus, mitochondrial factors such as the $50 \mathrm{kDa}$ protein released from mitochondria may cause apoptosis in vivo only in the presence of sufficient residual energy charge. An alternative role for mitochondria has been recently proposed by studies performed in the laboratories of Drs Wang, Green and Newmayer (Kluck et al, 1997; Yang et al, 1997), who have suggested that pores may form on the outer mitochondrial membrane through which holocytochrome c (the heme complexed form of cytochrome c) can enter the cytosol and subsequently participate in the activation of caspases involved in the execution of apoptosis (Figure 2). This step would not require a complete and irreversible loss of mitochondrial membrane potential and may be upstream or independent from the proteolytic activity observed by Kroemer and his collaborators.

\section{Mitochondria in neuronal apoptosis and necrosis}

The duration and extent of $\mathrm{Ca}^{2+}$ influx may determine whether neurons survive, die by apoptosis, or undergo necrotic lysis (Choi, 1995). According to this paradigm, continuous, but moderate increases in $\left[\mathrm{Ca}^{2+}\right]_{i}$ such as those produced by a sustained slow influx or a transient massive overload may cause apoptosis, whereas an exceedingly high influx rate would cause rapid cell lysis. For instance, stimulation of cortical neurons with high concentrations of NMDA results in necrosis, whereas exposure to lower concentrations causes apoptosis (Bonfoco et al, 1995). Correspondingly, neuronal death in experimental stroke models is necrotic in the ischemic core, but delayed and apoptotic in the less severely compromised penumbra or border regions ( $\mathrm{Li}$ et al, 1995; Charriaut-Marlangue et al, 1996). The sensors that switch neurons towards one or the other fate may be multiple. However, there is reason to believe some may be related to mitochondrial function (Ankarcrona et al, 1995). We have recently investigated the occurrence of apoptosis in an in vitro model of excitotoxicity: CGCs exposed to glutamate. Low concentrations of glutamate (i.e., 1-10 $\mu \mathrm{M}$ ) triggered exclusively apoptosis, whereas with higher glutamate concentrations most neurons underwent rapid necrosis. The mechanisms deciding whether exposure of cerebellar granule cells to glutamate results in apoptosis or necrosis were also investigated. The experiments revealed that during and shortly after exposure to glutamate, a subpopulation of neurons died by necrosis. In these cells, mitochondrial membrane potential and energy stores collapsed, nuclei swelled and cellular debris were scattered in the incubation medium. Neurons surviving the early necrotic phase recover mitochondrial potential and energy levels. Later, they underwent apoptosis, as shown by the formation of apoptotic nuclei and chromatin degradation into high and low molecular weight fragments. These results suggested that the degree of mitochondrial dysfunction and/or the maintenance of sufficient energy levels were critical factors in determining the mode of neuronal death in this system. Moderate or transient 
mitochondrial damage induced directly by $\mathrm{Ca}^{2+}$-overload or by other as yet unknown upstream signals may actually contribute to the execution of apoptosis. However, a complete deenergization of the cell resulting from extensive mitochondrial damage and a concomitant inhibition of glycolysis would not allow the ordered sequence of changes required for the apoptotic demise. In such a case, death would occur by cell lysis/necrosis.

Necrosis

Apoptosis
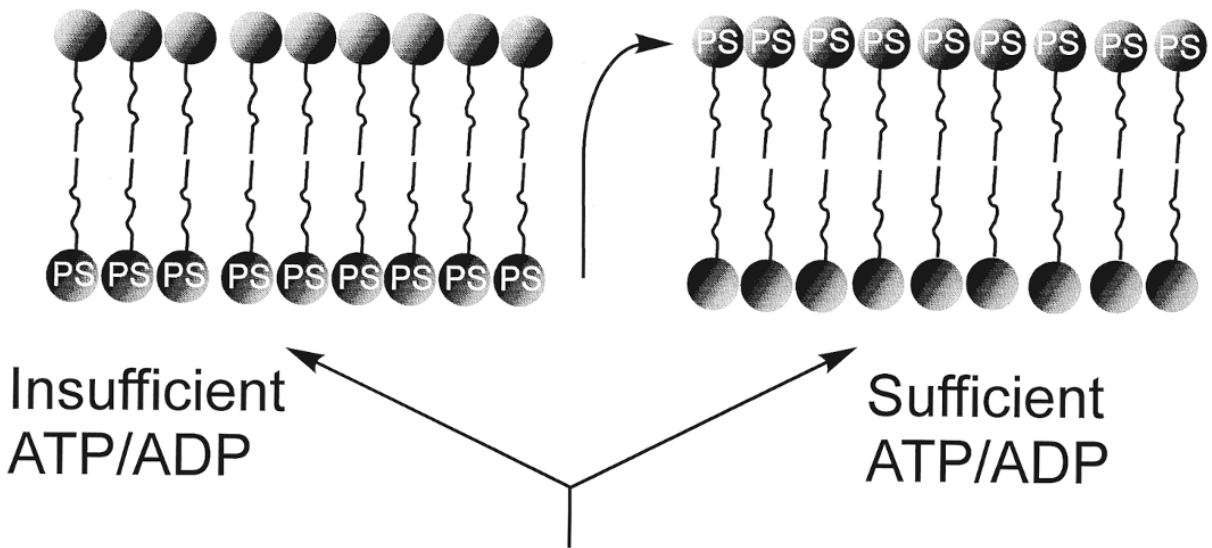

Signals for cell death

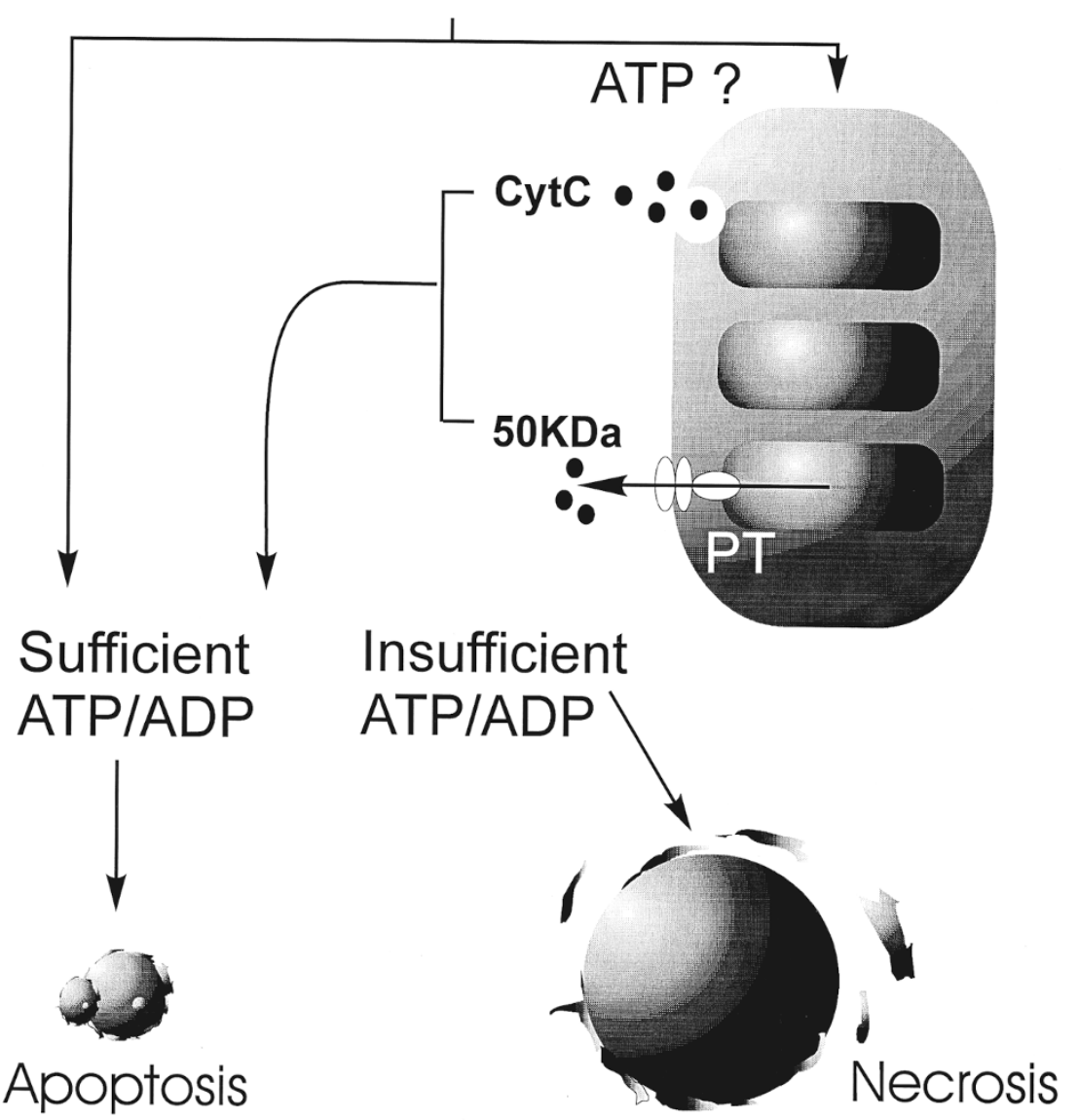

Figure 2 ATP as a switch in the decision between apoptosis and necrosis. Signals for cell death may activate initial common pathways involving both mitochondrial and non-mitochondrial pathways. Depending on the intracellular ATP/ADP level, the shape of cell demise can change from apoptosis to necrosis. At least two processes occurring in apoptosis seem to require adequate energy sources: (i) chromatin condensation, with proteolytic cleavage of some nuclear proteins by caspases (bottom); (ii) surface appearance of phosphatidylserines (PS) required for the recognition of apoptotic cells by scavenger cells. Proteins released by mitochondria include holocytochrome $\mathrm{c}(\mathrm{Cyt} \mathrm{C})$ and the $50 \mathrm{KDa}$ protein known as apoptosis-inducing factor (Kroemer, 1997). The latter is released during permeability transition (PT). 
Therefore, it seems likely that apoptosis ensues under condition, where sufficient energy production remains to execute an internal 'death programme' (Figure 2). A common finding in apoptosis is for example that of morphologically intact mitochondria (Wyllie et al, 1980; Hajos et al, 1986; Bohlinger et al, 1996), which may be energised by electron transport or by import of cytoplasmic ATP. Accordingly, ATP levels are maintained in different neuronal populations undergoing apoptosis (Rothman et al, 1987; Ankarcrona et al, 1995; Mills et al, 1995).

\section{A role for ATP generation in the decision between apoptosis or necrosis}

While apoptosis and necrosis have clearly distinguishing morphological and biochemical features (Kerr et al, 1972), it is becoming clear that they may share: (i) initial events, like receptor signalling (Ankarcrona et al, 1995; Laster et al, 1988; Leist et al, 1997c) (ii) some controlling systems including Bcl-2 and mitochondrial permeability transition (Shimizu et al, 1996; Myers et al, 1995; Rosser and Gores, 1995; Aguilar et al, 1996) and (iii) effectors like caspases (Shimizu et al, 1996; Künstle et al, 1997). Notably, in several pathological conditions (e.g. brain ischemia; Linnik et al, 1995; Beilharz et al, 1995; Portera-Cailliau et al, 1995; Charriaut-Marlangue et al, 1996), liver damage by cytokines or toxins (Leist et al, 1995, 1996, 1997b) demise can occur simultaneously by necrosis or apoptosis. Work in our laboratory and in collaboration with $\mathrm{Dr}$ SA Lipton and $\mathrm{Dr} S$ Orrenius has previously shown that the intensity of the same initial insult decides the prevalence of either apoptosis or necrosis (Dypbukt et al, 1994; Bonfoco et al, 1995). This suggests that while initial events may be common to both types of cell death, a certain metabolic condition would be required to activate downstream controllers which direct cells towards the organised execution of apoptosis (Figure 2).

Our previous work showed that intracellular energy levels are rapidly dissipated in necrosis, but not in apoptosis of neuronal cells (Ankarcrona et al, 1995). Thus, to investigate whether ATP availability was involved in the decision between apoptosis and necrosis, we clamped intracellular ATP levels using a paradigm of glucose deprivation/repletion in conjunction with a blocker of the mitochondrial ATP synthase, oligomycin. Lymphoid cells (Jurkat) were treated with two well known inducers of apoptosis: (i) anti-CD95 antibodies ( $\alpha$ CD95) that elicit apoptosis by activating cell surface CD95 receptors (Boldin et al, 1996, Muzio et al, 1996); (ii) the protein kinase inhibitor staurosporin (STS) that, at high concentrations, triggers apoptosis in a wide variety of mammalian cells (Weil et al, 1996). Neither of these stimuli requires a functional respiratory chain for the induction of apoptosis (Jacobson et al, 1993; Anel et al, 1996).

Our results showed that ATP is required for the progression of apoptosis (Figure 2). In conditions of ATP depletion, cells treated with either STS or CD95 underwent necrosis. Selective and graded repletion of the extramitochondrial ATP pool with glucose prevented necrosis and restored the ability of cells to undergo apoptosis. Maintenance of a certain ATP level may have simply prevented an early, passive breakdown of the plasma membrane. In this case, the development of apoptosis, which would not necessarily require ATP, could have been precluded by a premature demise with apparent necrotic features. However, we found that necrosis elicited by either STS or CD95 in ATP-depleted cells occurred with a similar or rather longer time course than apoptosis, suggesting that an active step was required for the progression of apoptosis. Using a paradigm of pulsed ATP-depeletion/ repletion, we then showed that ATP generation either by glycolysis or by mitochondria was required for at least two events in apoptosis: the active execution of the final phase of apoptosis, which involves nuclear condensation and DNA degradation and the expression of membrane phosphatidylserines (Leist et al, 1997c) required for the recognition of apoptotic cells by macrophages (Figure 2).

Differences in the fate of the nucleus were epitomised by the selective degradation of lamins in apoptosis (Figure 3). This process pivotal for nuclear collapse in many systems (Oberhammer et al, 1994; Neamati et al, 1995; Ankarcrona et al, 1996) is effected by the activation of caspases or other proteases during apoptosis (Lazebnik et al, 1995; Voelkel-Johnson et al, 1995; Zhivotovsky et al, 1995). In necrosis observed under conditions of ATP-depletion, caspase-mediated cleavage of lamin B was instead significantly reduced (Figure 3 ). This suggests that at least one component of nuclear degradation observed in apoptosis may require ATP-dependent steps for the activation and possibly the translocation of caspases into the nucleus. Recent work in Dr Orrenius' laboratory has indeed suggested that ATP is required for part of the nuclear changes elicited by cytosol extracted from CD95treated cells (Kass et al, 1996). Nuclear $\mathrm{Ca}^{2+}$ uptake is also an energy requiring process and while characterising the $\mathrm{Ca}^{2+}$ dependent endonuclease activity in collaboration with Dr Orrenius (Jones et al, 1989), we showed that nuclei can

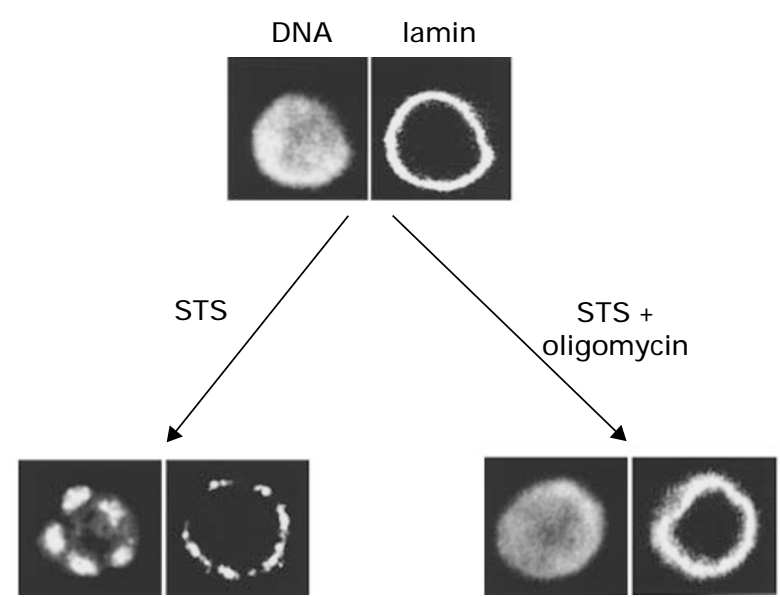

Figure 3 Prevention of lamin breakdown by ATP-depletion. Control cells (top) were treated with staurosporine (STS) or staurosporine plus oligomycin. Images were taken by confocal microscopy after immunocytochemical staining of lamin B (lamin) and DNA-staining with H-33342. Control cells and STS plus oligomycin-treated cells (necrotic) showed the typical circular lamin structure around non-condensed chromatin, while STS-treated (apoptotic) cells displayed chromatin condensation and fragmentation, associated with breakdown of the lamin nucleoskeleton. 
sequester $\mathrm{Ca}^{2+}$ in an energy-dependent manner (Nicotera et al, 1989, 1990). Notably, recent reports have shown that apoptosis suppression by $\mathrm{Bcl}-2$ correlates with its ability to reduce nuclear $\mathrm{Ca}^{2+}$ uptake (Marin et al, 1996; McConkey, 1996).

One relevant feature of apoptosis is the relatively efficient removal of apoptotic bodies (Savill et al, 1993). Notably, apoptotic cells are not only removed by 'professional' macrophages, but also by 'normal' neighbouring cells e.g. in $C$. elegans, in many tumours, and in hepatocytes. Recognition and removal of dead cells is one of the most relevant features in apoptosis with respect to its value in limiting adverse effects in the neighbouring tissue. In view of these considerations, the finding that, in our experimental paradigm, early expression of phosphatidylserines is dependent on ATP and it is restricted to apoptotic cells has important implications (Leist et al, 1997c) (Figure 2).

\section{Conclusions}

During the last couple of years it has become clear that mitochondria play an important role in apoptosis. The 'cytoplasmic controller' (Jacobson et al, 1994) implicated in the activation of downstream events resulting in the typical apoptotic features including proteolysis of nuclear elements and DNA degradation may either directly originate from mitochondria (Kroemer, 1997) or require a mitochondrial factor for its activation (Kluck et al, 1997; Yang et al, 1997). This would also explain several observations of the protective effect of antiapoptotic proteins such as $\mathrm{Bcl}-2$ or $\mathrm{Bcl}-\mathrm{x}_{\mathrm{L}}$, which would act on the mitochondria (Golstein, 1997; Kroemer, 1997; Tsujimoto, 1997).

While not all pathways leading to cell death may necessarily involve mitochondria, several could activate upstream effectors/controllers that converge in their actions on mitochondria. This would cause permeability transition and/or permeabilization of the mitochondrial outer membrane (a pore forming protein deprived of an inhibitory partner? Golstein, 1997). Our findings suggest that either the upstream controller or the execution system(s) downstream of the mitochondria can be modulated by the availability of ATP (Ankarcrona et al, 1995; Leist et al, 1997c). The latter may be provided by glycolysis or, in tissues with high metabolic demand, primarily by energized mitochondria.

Thus, apoptosis and necrosis would be two extremes of a continuum of possible types of cell demise, whose shape and implications for the neighbouring tissue would be decided by the availability of ATP in addition to other factors in the dying cell and in scavenger cells. This would explain the frequent coexistence of both types of demise in pathological situations where individual cell death within the tissue would be decided by the energy supply. While it appears useful for multicellular organisms that physiological cell death occurs by apoptosis, it would be tempting to speculate that selection of apoptosis and necrosis may not be casual. Certain pathological conditions (i.e. pathogen infections) may require a rapid inflammatory response to clear the pathogen. In this case, the recruitment of a systemic defence system involving infiltration, inflammation and also some additional tissue damage may be beneficial. Under these circumstances death by necrosis, which does not apparently lead to expression of surface recognition signals would be a better choice. Thus, apoptosis and necrosis could be seen not only as different forms of demise in individual cells, but they may reflect the decision of the tissue or organism, between a local, silent or a global, disruptive reaction.

\section{Acknowledgements}

This study was supported by the EEC grants ENV4-CT96-0169 and 12029-97-06F1ED-ISPD and the AFF University of Konstanz grant 27/95.

\section{References}

Abe K, Aoki M, Kawagoe J, Yoshida T, Hattori A, Kogure K and Itoyama Y (1995) Ischemia delayed neuronal death. A mitochondrial hypothesis. Stroke 26: $1478-1489$

Aguilar HI, Botla R, Arora AS, Bronk SF and Gores GJ (1996) Induction of the mitochondrial permeability transition by protease activity in rats: a mechanism of hepatocyte necrosis. Gastroenterol. 110: 558-566

Anel A, Gamen S, Alava MA, Schmitt-Verhulst A-M, Pineiro A and NavalJ (1996) Role of oxidative damage and IL-1 beta-converting enzyme-like proteases in Fasbased cytotoxicity exerted by effector T cells. Int. Immunol. 8: 1173-1183

Ankarcrona M, Dypbukt JM, Bonfoco E, Zhivotovsky B, Orrenius S, Lipton SA and Nicotera P (1995) Glutamate-induced neuronal death: a succession of necrosis or apoptosis depending on mitochondrial function. Neuron 15: 961-973

Ankarcrona M, Zhivotovsky B, Holmström T, Diana A, Eriksson J, Orrenius S and Nicotera P (1996) Lamin and -tubulin fragmentation precede chromatin degradation in glutamate-induced neuronal apoptosis. NeuroReport 7: 26592664

Beal MF, Hyman BT and Koroshetz W (1993) Do defects in mitochondrial energy metabolism underlie the pathology of neurodegenerative diseases? Trends Neurosci. 16: 125-131

Beilharz EJ, Williams CE, Dragunow M, Sirimanne ES and Gluckman PD (1995) Mechanisms of delayed cell death following hypoxic-ischemic injury in the immature rat: evidence for apoptosis during selective neuronal loss. Mol. Brain Res. 29: 1-14

Beneviste H, Drejer J, Schousboe A and Diemer NH (1984) Elevation of the extracellular concentration of glutamate and aspartate in rat hippocampus during transient cerebral ischemia monitored by introcerebral microdialysis. J. Neurochem. 43: 1369-1374

Bohlinger I, Leist M, Gantner F, Angermüller S, Tiegs G and Wendel A (1996) DNAfragmentation in mouse organs during endotoxic shock. Am. J. Pathol. 149: $1381-1393$

Boldin MP, Goncharov TM, Goltsev YV and Wallach D (1996) Involvement of MACH, a novel MORT1/FADD-interacting protease, in Fas/APO-1- and TNF receptorinduced cell death. Cell 85: 803-815

Bonfoco E, Krainc D, Ankarcrona M, Nicotera P and Lipton SA (1995) Apoptosis and necrosis: two distinct events induced respectively by mild and intense insults with NMDA or nitric oxide/superoxide in cortical cell cultures. Proc. Natl. Acad. Sci. USA 92: $72162-72166$

Bonfoco E, Leist M, Zhivotovsky B, Orrenius S, Lipton SA and Nicotera $P$ (1996) Cytoskeletal breakdown and apoptosis elicited by NO-donors in cerebellar granule cells require NMDA-receptor activation. J. Neurochem. 67: $2484-2493$

Bredesen DE (1995) Neural Apoptosis. Ann. Neurology 38: 839-851

Budd SL and Nicholls DG (1996a) A reevaluation of the role of mitochondria in neuronal $\mathrm{Ca}^{2+}$ homeostasis. J. Neurochem 66: 403-411

Budd SL and Nicholls DG (1996b) Mitochondria, calcium regulation, and acute glutamate excitotoxicity in cultured cerebellar granule cells. J. Neurochem. 67 $2282-2291$ 
Bullock R, Zauner A, Myseros JS, Marmarou A, Woodward JJ and Young HF (1995) Evidence for prolonged release of excitatory amino acid in serve human head trauma Relationship to clinical events. Ann. NY. Acad. Sci. 765: 290-297

Chao CC, Hu S, Ehrlich L and Peterson PK (1995) Interleukin-1 and tumor necrosis factor-alpha synergistically mediate neurotoxicity: involvement of nitric oxide and of N-methyl-D-aspartate receptors. Brain Behavior and Immunity 9: 355 365

Charriaut-Marlangue C, Margaill I, Borrega F, Plotkine M and Ben-Ari Y (1996) NG-nitro L-arginine methylester reduces necrotic but not apoptotic cell death induced by reversible focal ischemia in the rat. Eur. J. Pharmacol. 310: $137-140$

Cheng B, Christakos S and Mattson MP (1994) Tumor necrosis factors protect neurons against metabolic-excitotoxic insults and promote maintenance of calcium homeostasis. Neuron 12: $139-153$

Cheng B and Mattson MP (1991) NGF and bFGF protect rat hippocampal and human cortical neurons against hypoglycemic damage by stabilizing calcium homeostatsis. Neuron 7: 1031-1041

Cheng B and Mattson MP (1992) IGF-I and IGF-II protect cultured hippocampal and septal neurons against calcium-mediated hypoglycemic damage. J. Neurosci. 12: $1558-1566$

Choi DW (1988) Glutamate neurotoxicity and diseases of the nervous system. Neuron 1: 623-634

ChoiDW (1992) Bench to bedside: the glutamate connection. Science 258:241-243

Choi DW (1995) Calcium: still center-stage in hypoxic-ischemic neuronal death. Trends Neurosci. 18: 58-60

Coyle JT and Puttfarcken P (1993) Oxidative stress, glutamate, and neurodegenerative disorders. Science 262: 689-695

Drejer J, Beneviste H, Diemer NH and Schousboe A (1985) Cellular origin of ischemia-induced glutamate release from brain tissue in vivo and in vitro. J. Neurochem. 45: 145-151

Dugan LL, Sensi SL, Canzoniero LMT, Handran SD, Rothman SM, Lin T-S, Goldberg MP and Choi DW (1995) Mitochonrial production of reactive oxygen species in cortical neurons following exposure to N-methyl-D-aspartate. J. Neurosci. 15: $6377-6388$

Dykens JA (1994) Isolated cerebral and cerebellar mitochondria produce free radicals when exposed to elevated $\mathrm{Ca}^{2+}$ and $\mathrm{Na}^{2+}$ : implications for neurodegeneration. J. Neurochem. 63: 584-591

Dypbukt JM, Ankarcrona M, Burkitt M, Sjöholm A, Ström K, Orrenius S and Nicotera P (1994) Different prooxidant levels stimulate growth, trigger apoptosis, or produce necrosis of insulin-secreting RINm5F cells. J. Biol. Chem. 269: 30533-30560

Fahn S and Cohen G (1992) The oxidant stress hypothesis in parkinson's disease: evidence supporting it. Ann. Neurol. 32: 804-812

Fassbender K, Rossol S, Kammer T, Daffertshofer M, Wirth S, Dollman M and Hennerici M (1994) Proinflammatory cytokines in serum of patients with acute cerebral ischemia: kinetics of secretion and relation to the extent of brain damage and outcome of disease. J. Neurolog. Sci. 122: 135-139

Garthwaite G and Garthwaite J (1986) Amino acid neurotoxicity: intracellular sites of calcium accumulation associated with the onset of irreversible damage to rat cerebellar neurones in vitro. Neurosci. Lett. 71: 53-58

Golstein P (1997) Controlling cell death. Science 275: 1081 - 1082

Gross SS and Wolin MS (1995) Nitric oxide: pathophysiological mechanisms. Annu. Rev. Physiol. 57: 737-769

Gunter TE, Gunter KK, Sheu S and Gavin CE (1994) Mitochondrial calcium transport: physiological and pathological relevance. Am. J. Physiol. 267: C313-C339

Gunter TE and Pfeiffer DR (1990) Mechanisms by which mitochondria transport calcium. Am. J. Physiol. 258: C755-C786

Hajos F, Garthwaite $G$ and Garthwaite J (1986) lonic requirements for neurotoxic effects of excitatory amino acid analouges in rat cerebellar slices. Neurosci. 18: $437-447$

Hartley A, Stone JM, Heron C, Cooper JM and Schapira AHV (1994) Complex I Inhibitors induce dose-dependent apoptosis in PC12 cells: relevance to Parkinson's disease. J. Neurochem. 63: 1987-1990

Jacobson MD, Burne JF, King MP, Miyashita T, Reed JC and Raff MC (1993) Bcl-2 blocks apoptosis in cells lacking mitochondrial DNA. Nature 361: 365-369

Jacobson MD, Burne JF and Raff MC (1994) Programmed cell death and Bcl-2 protection in the absence of a nucleus. EMBO J. 13: 1899-1910

Jones DP, McConkey DJ, Nicotera P and Orrenius S (1989) Calcium-activated DNA fragmentation in rat liver nuclei. J. Biol. Chem. 264: 6398-6403
Kass GEN, Eriksson JE, Weis M, Orrenius S and Chow SC (1996) Chromatin condensation during apoptosis requires ATP. Biochem. J. 318: 749-752

Kass GEN, Wright JM, Nicotera P and Orrenius S (1988) The mechanism of 1-Methyl4-phenyl-1,2,3,6-tetrahydropyridine toxicity: role of intracellular calcium. Arch. Biochem. Biophys. 260: 789-797

Kerr JF, Wyllie AH and Currie AR (1972) Apoptosis: A basic biological phenomenon with wide ranging implications in tissue kinetics. Br. J. Cancer 26: $239-247$

Kiedrowski L and Costa E (1995) Glutamate-induced destabilization of intracellular calcium concentration homeostasis in cultured cerebellar granule cells: role of mitochondria in calcium buffering. Mol. Pharmacol. 47: 140-147

Kluck RM, Bossy-Wetzel E, Green DR and Newmeyer DD (1997) The release of cytochrome c from mitochondria: a primary site for bcl-2 regulation of apoptosis. Science 275: $1132-1136$

Kroemer G (1997) Mitochondrial implication in apoptosis. Cell Death Differ. 4:443456

Künstle G, Leist M, Uhlig S, Revesz L, Feifel R, MacKenzie A and Wendel A (1997) ICE-protease inhibitors block murine liver injury and apoptosis caused by CD95 or TNF-alpha. Immunol. Lett. 55: 5-10

Lafon-Cazal M, Pietri S, Culcasi M and Bockaert J (1993) NMDA-dependent superoxide production and neurotoxicity. Nature 364: 535-537

Laster SM, Woods JG and Gooding LR (1988) Tumor necrosis factor can induce both apoptotic and necrotic forms of cell lysis. J. Immunol. 141: 2629-2634

Lazebnik YA, Takahashi A, Moir RD, Goldman RD, Poirier GG, Kaufmann SH and Earnshaw WC (1995) Studies of the lamin proteinase reveal multiple parallel biochemical pathways during apoptotic execution. Proc. Natl. Acad. Sci. USA. 92: $9042-9046$

Legendre P, Rosenmund C and Westbrook GL (1993) Inactivation of NMDA channels in cultured hippocampal neurons by intracellular calcium. J. Neurosci. 13:674684

Leist M, Gantner F, Bohlinger I, Tiegs G, Germann PG and Wendel A (1995) Tumor necrosis factor-induced hepatocyte apoptosis precedes liver failure in experimental murine shock models. Am. J. Pathol. 146: 1220-1234

Leist M, Gantner F, Künstle G, Bohlinger I, Tiegs G, Bluethmann $\mathrm{H}$ and Wendel A (1996) The $55 \mathrm{kD}$ tumor necrosis factor receptor and CD95 independently signal murine hepatocyte apoptosis and subsequent liver failure. Mol. Med. 2:109-124

Leist M, Fava E, Montecucco C and Nicotera P (1997a) Peroxynitrite and NO-donors induce neuronal apoptosis by eliciting autocrine excitotoxicity. Eur. J. Neurosci. in press

Leist M, Gantner F, Naumann H, Bluethmann H, Vogt K, Brigelius-Flohe R, Nicotera P, Volk Hand Wendel A (1997b) Tumor necrosis factor-induced apoptosis during poisoning with hepatotoxins. Gastroenterol. 97: 924-935

Leist M, Single B, Castoldi AF, Kühnle S and Nicotera P (1997c) Intracellular ATP concentration: a switch deciding between apoptosis and necrosis. J. Exp. Med. 185:1481-1486

Li Y, Sharov VG, Jiang N, Zaloga C, Sabbah HN and Chopp M (1995) Ultrastructural and light microscopic evidence of apoptosis after middle cerebral artery occlusion in the rat. Am. J. Pathol. 146: 1045-1051

Linnik MD, Miller JA, Sprinkle-Cavallo J, Mason PJ, Thompson FY, Montgomery LR and Schroeder KK (1995) Apoptotic DNA fragmentation in the rat cerebral cortex induced by permanent middle cerebral artery occlusion. Mol. Brain Res. 32: $116-124$

Lipton SA and Rosenberg PA (1994) Excitatory amino acids as a final common pathway for neurologic disorders. New Engl. J. Med. 330: 613-622

Liu X, Kim CN, Yang J, Jemmerson R and Wang X (1996) Induction of apoptotic program in cell-free extracts: requirement for dATP and cytochrome c. Cell 86 : $147-157$

Marin MC, Fernandez A, Bick RJ, Brisbay S, Buja LM, Snuggs M, McConkey DJ, von Eschenbach AC, Keating MJ and McDonnell TJ (1996) Apoptosis suppression by $\mathrm{Bcl}-\mathrm{s}$ is correlated with the regulation of nuclear and cytosolic $\mathrm{Ca}^{2+}$. Oncogene 12: 2259-2266

Mattson MP, Barger SW, Begley JG and Mark RJ (1995) Calcium, free radicals, and excitotoxic neuronal death in primary cell culture. Meth. Cell. Biol. 46: 187-216

McConkey DJ (1996). Calcium-dependent, interleukin 1-converting enzyme inhibitor-insensitive degradation of lamin B1 and DNA fragmentation in isolated thymocyte nuclei. J. Biol. Chem. 271: 22398-22406

Meldrum B and Garthwaite J (1990) Excitatory amino acid neurotoxicity and neurodegenerative disease. Trends Pharmacol. Sci. 11: 379-387 
Mills JC, Nelson D, Erecinska M and Pittman RN (1995) Metabolic and energetic changes during apoptosis in neural cells. J. Neurochem. 65: 1721-1730

Mitrovic B, Martin FC, Charles AC, Ignarro LJ, Anton PA, Shanahan F and Merrill JE (1994) Neurotransmitters and cytokines in CNS pathology. In: FJ Seil, ed. Progress in Brain Research, vol. 103, chapt. 26. Amsterdam: Elsevier Science BV, pp. 319-330

Muzio M, Chinnaiyan AM, Kischkel FC, O'Rourke K, Shevchenko A, Ni J, Scaffidi C, Bretz JD, Zhang M, Gentz R, Mann M, Krammer PH, Peter ME and Dixit VM (1996) FLICE, a novel FADD-homologous ICE/CED-3-like protease, is recruited to the CD95 (Fas/APO-1) death-inducing signaling complex. Cell 85: 817-827

Myers KM, Fiskum G, Liu Y, Simmens SJ, Bredesen DE and Murphy AN (1995) Bcl-2 protects neural cells from cyanide/aglycemia-induced lipid oxidation, mitochondrial injury, and loss of viability. J. Neurochem. 65: 2432-2440

Neamati N, Fernandez A, Wright S, Kiefer J and McConkey DJ (1995) Degradation of Lamin B1 precedes oligonucleosomal DNA fragmentation in apoptotic thymocytes and isolated thymocyte nuclei. J. Immunol. 154: 3788-3795

NewmeyerDD, Farschon DM and Reed JC (1994)Cell-free apoptosis in xenopus egg extracts: inhibition by bcl-2 and requirement for an organelle fraction enriched in mitochondria. Cell 79: 353-364

Nicotera P, McConkey DJ, Jones DP and Orrenius S (1989) ATP stimulates $\mathrm{Ca}^{2+}$ uptake and increases the free $\mathrm{Ca}^{2+}$ concentration in isolated rat liver nuclei. Proc. Natl. Acad. Sci. USA. 86: 453-457

Nicotera P, Orrenius S, Nilsson T and Berggren P-O (1990) An inositol 1,4,5triphosphate-sensitive $\mathrm{Ca}^{2+}$ pool in liver nuclei. Proc. Natl. Acad. Sci. USA. 87 $6858-6862$

Novelli A, Reilly JA, Lysko PG and Henneberry RC (1988) Glutamate becomes neurotoxic via the $\mathrm{N}$-methyl-D-aspartate receptor when intracellular energy levels are reduced. Brain Res. 451: 205-212

Oberhammer FA, Hochegger K, Fröschl G, Tiefenbacher R and Pavelka M (1994) Chromatin condensation during apoptosis is accompanied by degradation of lamin $A+B$, without enhanced activation of cdc2 kinase. J. Cell. Biol. 126: 827 837

Philippon V, Vellutini C, Gambarelli D, Harkiss G, Arbuthnott G, Metzger D, Roubin R and Filippi $P$ (1994) The basic domain of the lentiviral tat protein is responsible fo damages in mouse brain: involvement of cytokines. Virology 205: 519-529

Portera-Cailliau C, Hedreen JC, Price DL and Koliatsos VE (1995) Evidence for apoptotic cell death in Huntington disease and excitotoxic animal models. $J$ Neurosci. 15: 3775-3787

Prehn JHM, Bindokas VP, Marcuccilli CJ, Krajewski S, Reed JC and Miller RJ (1994) Regulation of neuronal Bcl-2 protein expression and calcium homeostasis by transforming growth factor type beta confers wide-ranging protection on rat hippocampal neurons. Proc. Natl. Acad. Sci. USA. 91: 12599-12603

Reynolds IJ and Hastings TG (1995) Glutamate induces the production of reactive oxygen species in cultured forebrain neurons following NMDA receptors activation. J. Neurosci. 15: 3318-3327

Rosenmund C and Westbrook GL (1993) Calcium-induced actin depolymerization reduces NMDA channel activity. Neuron 10: 805-814

Rosser BG and Gores GJ (1995) Liver cell necrosis: cellular mechanisms and clinical implications. Gastroenterol. 108: 252-275

Rothman S (1984) Synaptic release of excitatory amino acid neurotransmitter mediates anoxic neuronal death. J. Neurosci. 4: 1884-1891
Rothman SM, Thurston JH and Hauhart RE (1987) Delayed neurotoxicity of excitatiory amino acids in vitro. Neurosci. 22: $471-480$

Rothstein JD, Dykes-Hoberg M, Pardo CA, Bristol LA, Jin L, Kuncl PW, Kanai Y, Hediger MA, Wang Y, Schielke JP and Welty DF (1996) Knockout of glutamate transporters reveals a major role for astroglial transport in excitotoxicity and clearance of glutamate. Neuron 16: $576-586$

Rutter GA, Theler J-M, Murgia M, Wollheim CB, Pozzan T and Rizzuto R (1993) Stimulated $\mathrm{Ca}^{2+}$ influx raises mitochondrial free $\mathrm{Ca}^{2+}$ to supramicromolar levels in a pancreatic beta-cell line. Possible role in glucose and agonist-induced insulin secretion. J. Biol. Chem. 268: 22385-22390

Sandberg M, Butcher SP and Hagberg H (1986) Extracellular overflow of neuroactive amino acids during severe insulin-induced hypoglycemia: in vivo dialysis of the rat hippocampus. J. Neurochem. 47: 178-184

Savill J, Fadok V, Henson P and Haslett C (1993) Phagocyte recognition of cells undergoing apoptosis. Immunol. Today 14: 131-136

Shimizu S, Eguchi Y, Kamiike W, Waguri S, Uchiyama Y, Matsuda H and Tsujimoto Y (1996) Retardation of chemical hypoxia-induced necrotic cell death by Bcl-2 and ICE inhibitors: possible involvement of common mediators in apoptotic and necrotic signal transductions. Oncogene 12: 2045-2050

Simon RP, Griffiths T, Evan MC, Swan JH and Meldrum BS (1984) Calcium overload in selectively vulnerable neurons of the hippocampus during and after ischemia: an electron microscopic study in the rat. J. Cerebr. Blood Flow Metabol. 4: $350-$ 361

Susin SA, Zamzami N, Castedo M, Hirsch T, Marchetti P, Macho A, Daugas E Geuskens M and Kroemer G (1996) Bcl-2 inhibits the mitochondrial release of an apoptogenic protease. J. Exp. Med. 184: 1331-1341

Tsujimoto Y (1997) Cell Death Differ. 4:429-434

Voelkel-Johnson C, Entingh AJ, Wold WSM, Gooding LR and Laster SM (1995) Activation of intracellular proteases is an early event in TNF-induced apoptosis. J. Immunol. 154: 1707-1716

Weil M, Jacobson MD, Coles HSR, Davies TJ, Gardner RL, Raff KD and Raff MC (1996) Constitutive expression of the machinery for programmed cell death. J. Cell. Biol. 133: 1053-1059

White RJ and Reynolds IJ (1995) Mitochondria and $\mathrm{Na}^{+} / \mathrm{Ca}^{2+}$ exchange buffer glutamate-induced calcium loads in cultured cortical neurons. J. Neurosci. 15 $1318-1328$

Wieloch T (1985) Hypoglycemia-induced neuronal damage prevented by an $\mathrm{N}$ methyl-D-aspartate antagonist. Science 230: 681-683

Wyllie AH, Kerr JF and Currie AR (1980) Cell death: the significance of apoptosis. Int. Rev. Cytol. 68: 251-306

Yang J, Liu X, Bhalla K, Kim CN, Ibrado AM, Cai J, Peng T, Jones DP and Wang X (1997) Prevention of apoptosis by Bcl-2: release of cytochrome c from mitochondria blocked. Science 275: 1129-1132

Zamzami N, Susin SA, Marchetti P, Hirsch T, Gómez-Monterrey I, Castedo M and Kroemer G (1996) Mitochondrial control of nuclear apoptosis. J. Exp. Med. 183: $1533-1544$

Zhivotovsky B, Gahm A, Ankarcrona M, Nicotera P and Orrenius S (1995) Multiple Protease are involved in thymocyte apoptosis. Exper. Cell. Res. 221: 404-412

Zoratti M and Szabò I (1995) The mitochondrial permeability transition. Biochim. Biophys. Acta. 1241: 139-176 